Article

\title{
Performance-Based Analysis of Single-Layer Cylindrical Steel Reticulated Shells in Fire
}

\author{
Zhiwei $\mathrm{Yu}^{1}{ }^{1}$, Chen $\mathrm{Lu}^{2, *}$ and Yiqin Zhong ${ }^{1}$ \\ 1 School of Civil Engineering, Guangzhou University, Guangzhou 510006, China; \\ yuzhiwei@gzhu.edu.cn (Z.Y.); braydenyu0701@hotmail.com (Y.Z.) \\ 2 School of Management, Guangzhou University, Guangzhou 510006, China \\ * Correspondence: luchen539@hotmail.com
}

Received: 20 March 2020; Accepted: 23 April 2020; Published: 29 April 2020

\begin{abstract}
With the rapid development of architectural technology, long-span structures have been widely used due to their vast interior space and beautiful architectural composition. Due to the characteristics and high costs of coating materials on large steel structures, fire resistance designs for these kinds of structures have become more and more important. This paper presents comprehensive case analyses of the fire performance of single-layer cylindrical reticulated shells. Nonuniform fire temperature fields of single-layer cylindrical reticulated shells in different fire scenarios were generated using a Fire Dynamics Simulator (FDS). The influences of different parameters on the air temperature field during a fire in a reticulated shell structure were analyzed. A Finite Element (FE) model was developed using the FE software ABAQUS to model the structural behavior of single-layer cylindrical reticulated shells in different fire scenarios. The effects of various parameters on the responses of single-layer cylindrical reticulated shells during a fire were investigated. Using the results from the performance-based analysis in this research, we propose some recommendations for fire resistance designs for single-layer cylindrical reticulated shells.
\end{abstract}

Keywords: reticulated shell; performance-based; fire resistance; fire scenario; structural behavior

\section{Introduction}

In China, fire is the third-worst major disaster causing a threat to human life and property (after drought and flooding), and its probability is much higher than that of other disasters. The loss of life and economic losses caused by fire are much higher than those caused by earthquakes. Fire is one of the most frequent and common major disasters threatening public safety. Long-span space structures, such as railway stations, airport terminal buildings, cinemas, stadiums, and exhibition halls are usually public buildings with dense populations or that contain dense material storage. The material of most space structures is steel, which has a poor fire resistance performance. High temperatures have a significant effect on the mechanical properties of steel. When the temperature exceeds $300^{\circ} \mathrm{C}$, the mechanical properties of steel decrease significantly. When the temperature is $400{ }^{\circ} \mathrm{C}$, the yield strength of steel is reduced to half of its yield strength at normal temperatures. When temperatures reach $600{ }^{\circ} \mathrm{C}$, steel basically loses its strength and stiffness. Therefore, the bearing capacity of structures decreases rapidly once a fire occurs. In a short period of time, high temperatures and smoke from fire can cause structural damage and even collapse. How to ensure the safety performance of steel space structures and reduce the economic losses from fire have become important issues for engineers and technicians engaged in theoretical research on spatial structures. However, the traditional fire resistance design method, which is based on a standard fire curve, cannot be used for long-span spatial structural designs because of the different characteristics of temperature fields within long-span spatial structures. Therefore, performance-based design methods have been used for the fire resistance 
designs of long-span spatial structures. In a performance-based fire resistance design, a fire model is established for specific structures. Changes in the air and structural temperature fields are simulated and calculated, considering a variety of material characteristics with different temperatures.

The temperature field within a large space structure is different from that a frame building. Therefore, the standard temperature-time curve is not suitable to represent the temperature distribution within large space structures. Some researchers have carried out a study on the temperature field of long-span spatial structures during a fire. The overall mechanical performance of structures in real fire scenarios has also been studied [1,2]. Du and Li [3] have put forward a new temperature curve for large structures based on an experimental and numerical analysis. Xue [4] has proposed a new formula for the calculation of air temperature in large structures on fire. Fan [5] has proposed a temperature field model considering the fire source, smoke plumes, and smoke layers to predict the temperature distribution within structures on fire (based on how fires develop) using a Fire Dynamics Simulator (FDS) [6]. The models and analysis mentioned can more accurately simulate the temperature distribution of the fires within large space structures. However, these simulations and models do not take the cooling process of a fire into consideration.

Currently, the researches on the structural response of large space steel reticulated shell structures under real fire scenarios are still limited, especially considering whole heating-cooling process. There have been some studies on the structural responses and performance-based design methods of fire in long-span spatial structures. Liu et al. [7] have conducted full-scale experiments on two steel truss structures. A finite element model for predicting the fire resistance capacity of long-span truss structures has also been established [8]. Bradford [9] has analyzed the fire resistance performance of a long-span flat steel arch and thereafter suggested certain fire resistance designs. P.J. Moss [10] has established a model of steel portal frame buildings using the finite element program SAFIR, which is based on New Zealand's Design Code. Pyl [11] has carried out a fire safety analysis of three-dimensional (3D) frame structures such as industrial halls using a full-scale fire test. The results of the predicted mechanical response were analyzed to ensure the model was applicable to daily design practice. $\mathrm{Lu}$ [12] has conducted a large number of case analyses on the high-temperature behaviors of large exhibition centers. Some suggestions have been made for the fire resistance design of steel truss structures. Richard [13] has carried out an advanced analysis on fire in a long-span arch frame using a performance-based fire resistance design method, considering different fire locations, spans, and possibilities for fire spread. Milke [14] has suggested objective requirements, including that the bearing capacity of the structure on fire be greater than the external load, that the deformation of the structure be less than the allowable deformation, and that the permanent damage caused by fire be minimized. Parkinson and Kodur have written about performance-based design requirements of structural steel for fire conditions [15]. They provided structural engineers a method that will facilitate the design of structural steel for fire conditions using a performance-based approach. The method has been proposed that allows the designer to predict the time-temperature relationship expected in a compartment fire with a reasonable level of conservatism, which can be used to determine the required level of protection. However, most previous studies on the fire resistance performance of large structures have focused on steel frame structures and truss structures. There is little research on the fire resistance performance of reticulated shells. From the authors' knowledge, the researches on the fire performance of large span reticulated shell structures under real fire scenarios are still very limited and further researches are needed.

This paper presents comprehensive case analyses on the fire resistance performance of single-layer cylindrical reticulated shells. Nonuniform fire temperature fields of single-layer cylindrical reticulated shells in different fire scenarios were generated using a Fire Dynamics Simulator (version 5, Baltimore, MD, USA). The influences of different parameters of the air temperature fields during fire-and how they affected the reticulated shell structure-were analyzed. Calculate the temperatures of the structural members within the large-space reticulated shell structure based on the local fire temperature fields. A finite element (FE) model was developed based on the studies [16-19] by using the FE 
software ABAQUS to model the structural behavior of single-layer cylindrical reticulated shells in different fire scenarios. The effects of various parameters on the responses of single-layer cylindrical reticulated shells during a fire were investigated. Using the results of the performance-based analyses in this research, we were able to create some guidance for the fire resistance design of single-layer cylindrical reticulated shells.

\section{Fire Scenario Designs for Reticulated Shells}

FDS (Fire Dynamics Simulator), which was developed by the National Institute of Standards and Technology (NIST), is a software for calculating fire dynamics. It is mainly dedicated to simulating and analyzing three-dimensional space fire problems, and it has an open program system and good post-processing functions. It has been widely used in the field of structural fire safety engineering. The calculation results were verified through experiments. In this paper, FDS was used to simulate the fire scenarios and calculate the air temperature in the reticulated shell model.

\subsection{Analysis Model}

A three-way single-layer cylindrical latticed shell is a typical long-span spatial structure. It is used commonly in industrial buildings, such as warehouses, for coal and wood storage. In this paper, a single-layer cylindrical latticed shell was established as the analysis model, as shown in Figure 1. In order to study the influence of the temperature field of a fire on single-layer cylindrical latticed shells, different parameters such as the rise-span ratio, roof weight, member sections, and thickness of the protective layer were used in the different analysis models. The length and the span of the cylindrical latticed shell were 24 and $15 \mathrm{~m}$, respectively. The rise-span ratio was 1/4, 1/3, and 1/2.

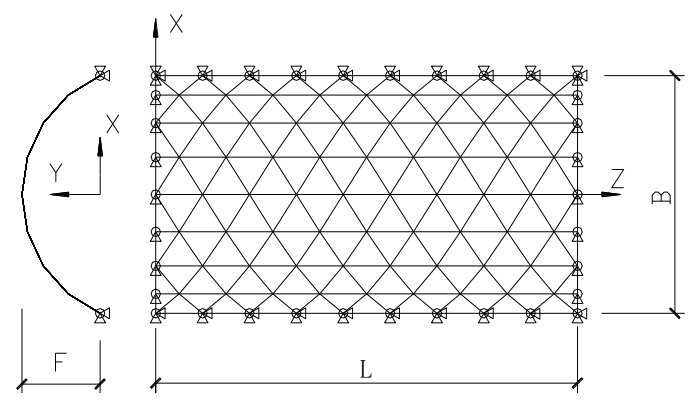

(a)

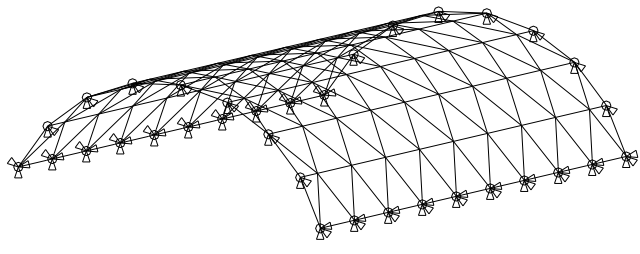

(b)

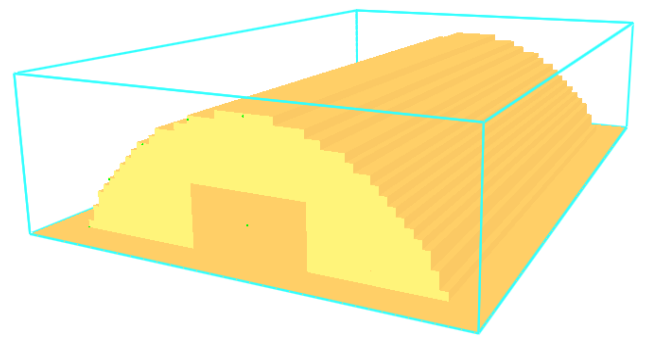

(c)

Figure 1. Analysis model of three-way, gridded, single-layer, cylindrical latticed shell. (a) Plan view of the analysis model; (b) three-dimensional (3D) view of the analysis model; (c) the analysis model in FDS.

\subsection{Fire scenario Design}

Fire scenario design is one of the most significant aspects of performance-based fire resistance design. It uses the most disadvantageous criteria as the bases for the design, which include the location 
and area of the fire source, the fire development model, and the maximum heat release rate (HRR) of the fire.

\subsubsection{Fire Sources}

Simulating flames and smoke from fire can be difficult. Fire conditions can be unpredictable due to numerous factors affecting the structural fire temperature field, such as the location of the fire source, the air temperature, surrounding circumstances, and atmospheric pressure. In order to simplify the simulations of the fire source, a method directly expressing the law of fire source power variation was utilized. In this paper, a Non-Premixed Combustion model (a model in which the entire fire combustion process is controlled by the power of the fire source) was used to simulate the fire source and to describe the combustion process of combustibles in the fire. A Non-Premixed Combustion Model can control the combustion heat and the heat release rate by simultaneously controlling the velocity of combustibles and oxidants entering the flow field.

The settings for "fire source" included the power of the fire source and the fire development process. The development of fire is a complicated issue. A fire in a building spreads from one part of a building to the entire building, which becomes an extended fire source. The locations we used for fire sources are shown in Figure 2.

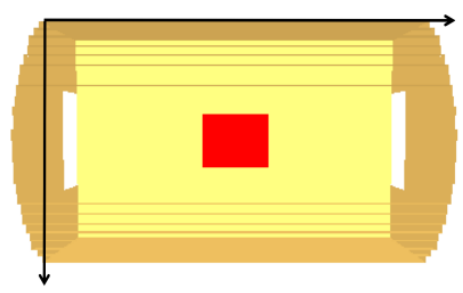

(a)

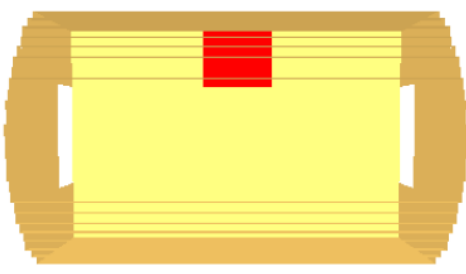

(b)

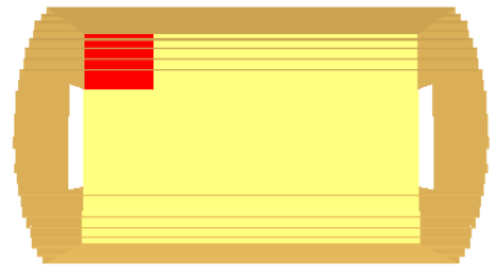

(c)

Figure 2. Fire source locations. (a) Location I-fire in the center; (b) location II-fire in the middle of the longitudinal side; (c) location III-fire at the corner.

\subsubsection{Maximum Heat Release Rate}

Fire development in a long-span spatial structure is very complicated. In this paper, the fire development curve was assumed to be constant when the heat release rate reached a maximum value, with consideration for a decay period within the fire source. The model for fire development is expressed as the relationship between the heat release rate and the duration of the fire, which is illustrated as the following equation:

$$
Q=\alpha t^{2}
$$

where $Q$ is the heat release rate $(\mathrm{kW}) ; \alpha$ is the fire growth rate $\left(\mathrm{kW} / \mathrm{s}^{2}\right)$; and $t$ is the duration of the fire(s). Given the fire development model, the expression of a fire's heat release rate in this paper is calculated according to Equation (2):

$$
Q=\left\{\begin{array}{cc}
\alpha t^{2} & \left(0 \leq t<t_{g}\right) \\
Q_{\max } & \left(t_{g} \leq t<2400 s\right) \\
\alpha^{\prime}(3600-t) & (2400 s \leq t \leq 3600 s)
\end{array}\right.
$$

where $t_{g}$ is the time required to reach a steady state and $Q_{\max }$ is the maximum heat release rate.

Chinese Technical Code for Fire Safety of Steel Structure in Buildings (CECS200) [20] stipulated the maximum heat release rates corresponding to different types of fire as shown in Table 1. The Code also stipulated the maximum heat release rates corresponding to different types of buildings. For a supermarket or warehouse without a sprinkler system, the maximum heat release rate was $20 \mathrm{MW}$. In order to carry out the parametric analysis of air temperature field, the parameters of the fire sources are shown in Table 1. 
Table 1. Types of heat release rate.

\begin{tabular}{cc}
\hline Types of Fire & Maximum Heat Release Rate $Q_{s} / \mathbf{M W}$ \\
\hline Small power fire & $<3.5$ \\
\hline Middle power fire & $3.5-15$ \\
\hline Large power fire & $>15$ \\
\hline
\end{tabular}

Due to the need for parametric analyses, the maximum heat release rate of the fire source was 10-20 MW. The fire growth rate $\alpha$ is $0.04689 \mathrm{~kW} / \mathrm{s}^{2}$ for the large power fire(fast fire) and the heat release rate per unit area (HRRPUA) $q_{e}$ was $1000 \mathrm{~kW} / \mathrm{m}^{2}$ in accordance with the U.S. Standards for Smoke and Heat Venting [20] and CECS200 [21]. Fire source areas can be calculated using the equation $A=Q_{\max } / q_{e}$. Since reticulated shells have requirements to store or display different items, different fire source areas were considered. The specific values of the parameters of the fire sources are shown in Table 2.

Table 2. Parameter settings of fire source. HRRPUA = heat release rate per unit area.

\begin{tabular}{|c|c|c|c|c|}
\hline$Q_{\max }(\mathrm{MW})$ & HRRPUA $\left(\mathrm{kW} / \mathrm{m}^{2}\right)$ & $A\left(\mathrm{~m}^{2}\right)$ & $\alpha\left(\mathrm{kW} / \mathrm{s}^{2}\right)$ & $t_{g}(\mathrm{~s})$ \\
\hline 10 & 1000 & $2.0 \times 5.0$ & 0.04689 & 461 \\
\hline 15 & 1000 & $3.0 \times 5.0$ & 0.04689 & 565 \\
\hline 16 & 1000 & $3.2 \times 5.0$ & 0.04689 & 584 \\
\hline 17 & 1000 & $3.4 \times 5.0$ & 0.04689 & 602 \\
\hline 18 & 1000 & $3.6 \times 5.0$ & 0.04689 & 620 \\
\hline 19 & 1000 & $3.8 \times 5.0$ & 0.04689 & 636 \\
\hline 20 & 1000 & $4.0 \times 5.0$ & 0.04689 & 650 \\
\hline
\end{tabular}

\section{Air Temperature Field Analysis During a Fire}

In this paper, we used the FDS (Fire Dynamics Simulator) software developed by the National Institute of Standards and Technology (NIST) to simulate fire. FDS is a software for calculating fire dynamics problems, and it is mainly used to simulate and analyze fire problems in three-dimensional space. It has an open program system and good post-processing functions, and it is widely used in the field of fire safety structural engineering. Our calculation results were also experimentally verified. A mesh setting is an essential part of FDS simulation calculations. All FDS calculations must be carried out based on meshing generation. Further, the size of the grid settings controls the accuracy of the simulation calculations and the length of the calculation time.

A proper mesh setting size is significant for simulations in FDS in order to minimize the calculation time and obtain the required calculation precision. The simulation accuracy of can be obtained by setting close or consistent length of mesh size in three directions of coordinate axis. The mesh size in FDS can be determined based on the numbers of grid respectively in $\mathrm{x}, \mathrm{y}$, and $\mathrm{z}$ directions, which are supposed to meet the module requirements of $2^{\mathrm{u}}, 3^{\mathrm{v}}$ or $5^{\mathrm{w}}$. The coefficients of $\mathrm{u}, \mathrm{v}$, and $\mathrm{w}$ are integers. According to the instructions of FDS, the mash size is determined according to the following empirical Equation (3), which is the function of initial condition and heat release rate.

$$
D^{\prime \prime}=\left(\frac{Q}{\rho_{\infty} \cdot c_{\infty} \cdot T_{\infty} \cdot \sqrt{g}}\right)^{2 / 5}
$$

$D^{\prime \prime} / \delta_{x} \in(4,16), D^{\prime \prime} / \delta_{y} \in(4,16), D^{\prime \prime} / \delta_{z} \in(4,16)$ where

$D^{\prime \prime}$ — equivalent fire source diameter $(\mathrm{m})$;

$Q$ - heat release rate of fire source $(\mathrm{kW})$;

g-gravitational acceleration, which is $9.8 \mathrm{~m} / \mathrm{s}^{2}$;

$\rho_{\infty}$ —initial environment air density, which is $1.290 \mathrm{~kg} / \mathrm{m}^{3}$;

$c_{\infty}$ — initial value of heat capacity, which is $1.4 \times 103 \mathrm{~J} .(\mathrm{kg} \cdot \mathrm{K})$; 
$T_{\infty}$ — initial environment temperature, which is $293 \mathrm{~K}$;

$\delta_{x}, \delta_{y}, \delta_{z}-$ mash size in $\mathrm{x}, \mathrm{y}$, and $\mathrm{z}$ direction, respectively.

In order to ensure the accuracy of the calculation results and reduction of the calculation time, the mash size is designated to be $0.2 \mathrm{~m} \times 0.2 \mathrm{~m} \times 0.2 \mathrm{~m}$ in this paper. When the maximum heat release rate of fire source is $20 \mathrm{~kW}$, the availability of the mash size can be proved based on the Equation (3) as follows:

$$
\begin{gathered}
D^{\prime \prime}=\left(\frac{Q}{\rho_{\infty} C_{p} T_{\infty} \sqrt{g}}\right)^{2 / 5}=\left(\frac{20000}{1.29 \times 1.4 \times 293 \times \sqrt{9.8}}\right)^{2 / 5}=2.71, \\
\frac{D^{\prime \prime}}{\delta x}=\frac{2.71}{0.2}=13.55 \in[4,16]
\end{gathered}
$$

\subsection{FDS Model Verification}

In order to verify the accuracy and applicability of FDS for fire simulation analysis, this paper carried out a comparison between the results of FDS simulation and fire test results. The test was carried out in a large space steel factory building located in Xuzhou, China. The length of the steel structure is $60 \mathrm{~m}$. The width of the structure is $30 \mathrm{~m}$. The highest and the lowest part of the roof is $9 \mathrm{~m}$ and $8 \mathrm{~m}$, respectively. There are two $5 \times 4 \mathrm{~m}^{2}$ doors at each of the two short sides and one $5 \times 4 \mathrm{~m}^{2}$ door at each of the two long sides of the structure. The geometry of the test model is shown in Figure 3. There are eight oil basins used as the fire source. The calorific value of diesel was $42,600 \mathrm{~kJ} / \mathrm{kg}$, the combustion efficiency and mass loss rate of diesel were $0.027 \mathrm{~kg} / \mathrm{s}$ and $93.9 \%$, respectively. The heat release rate of fire source is $1080 \mathrm{~kW}$. There are 18 thermocouples arranged at the top of the fire source, starting from $0.4 \mathrm{~m}$ above the fire source with an interval of $0.2 \mathrm{~m}$, which is used to record the temperature of flame and plume during the test.

The FDS model is established as shown in Figure 4. The number of grid is $150 \times 300 \times 45$, the mesh size is $0.2 \mathrm{~m} \times 0.2 \mathrm{~m} \times 0.2 \mathrm{~m}$. The door opening, windows, fire source area, and thermocouples are defined according to the test situation. According to the test, the initial temperature is $16^{\circ} \mathrm{C}$ and the simulation duration is $1400 \mathrm{~s}$. The FDS simulation results and the test results are compared by the temperature measured at the location $4 \mathrm{~m}$ above the fire source as shown in Figure 5.

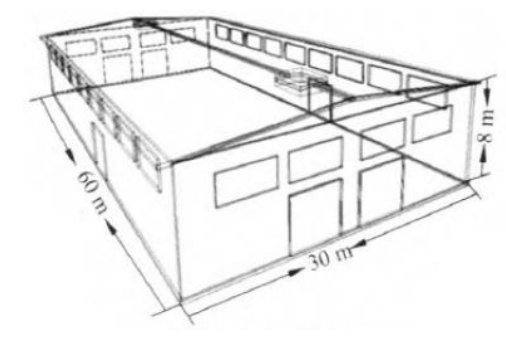

Figure 3. Geometry of the steel factory building.

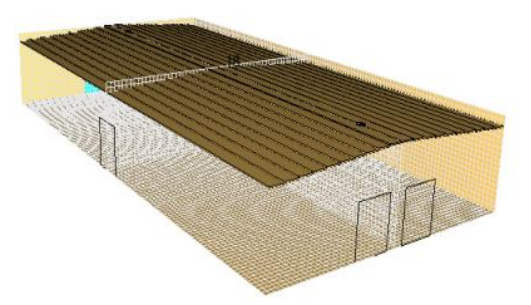

Figure 4. Fire Dynamics Simulator (FDS) Model. 


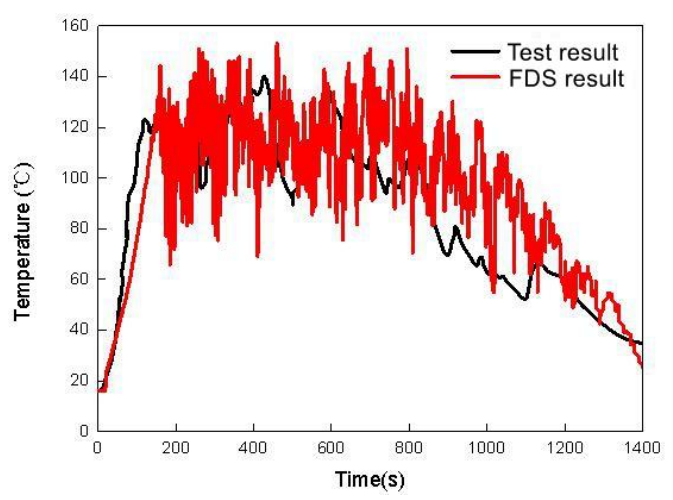

Figure 5. Comparison of temperature curves between test and FDS results.

The temperature value of FDS simulation is basically consistent with test result. The overall changing trend of flue gas temperature is similar to the test results as well. However, there are some differences between simulation and test results. The temperature obtained by FDS simulation is relatively large and higher than the measuring temperature in the test because of the following reasons: (1) the air leakage and environmental temperature fluctuation are inevitable in the test, which will make the test values lower than the simulation results. (2) Incomplete combustion of fuel exists in the test and the heat release rate decreases gradually, and (3) there are measurement errors in the test. From the above analysis, it is can be seen that the numerical value and variation trend of simulation and test results are relatively similar. Therefore, the accuracy and reliability of the simulation method can be verified.

In order to study the influence of different fire source locations on the internal temperature field of the reticulated shells, three different fire source locations were set up, as shown in Figure 2. For accuracy, the air temperature fields inside the reticulated shells of the three fire source locations were calculated.

\subsection{Fire source Location I}

When the fire source is in the center at ground level, the temperature field inside the reticulated shell is symmetrically distributed along the length and span of point A. The monitoring points A, B, and $C$, on the roof, are shown in Figure 6. Point $A$ is directly above the fire source. The air temperature curves of each monitoring point are shown in Figure 7.

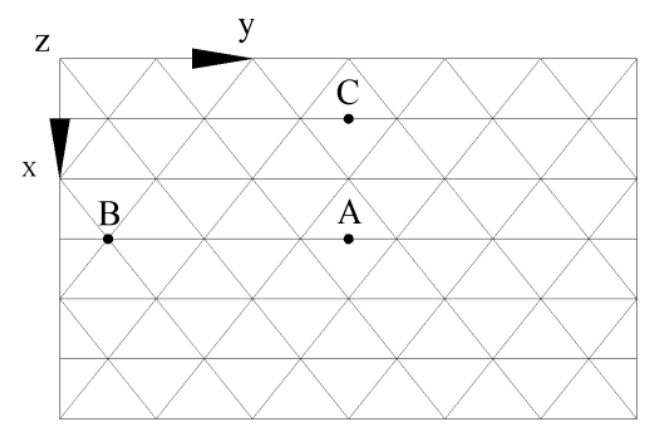

Figure 6. Part of the measurement points. 


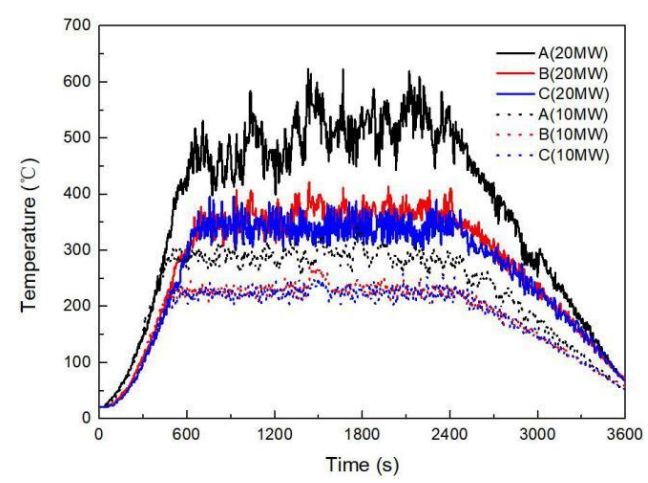

Figure 7. Air temperature at each monitoring point.

As shown in Figure 7, the temperature of the monitoring point indicates that the temperature of point $\mathrm{A}$ on the roof directly above the fire source is much higher than at the other two points. The temperature of point $B$ is higher than that at point $C$, which is due to the flow characteristics of the hot smoke. The hot smoke floats up and spreads along the height of the roof so that the temperature at point $B$ is higher than the temperature at point $C$ at the edge of the roof. In general, the air temperature increases with the increase of the power of the fire source and with the decrease of the distance from the center of the fire source. The air temperature directly above the fire source is much higher than that around the fire source. Therefore, this shows that a curved roof will cause the convergence of hot smoke. The convergence effect increases obviously with an increase in the fire source's power.

It can be seen that the temperature rise curve at the three measuring points is similar to the change form of the fire source power curve under each working condition in Figure 7. Due to the uncertainty of the flame height affected by the external environment during combustion, there are different degrees of fluctuations in each curve in the temperature stable stage. The fluctuation of the measuring point directly above the fire source is larger than that outside the fire source, and the fluctuation of the air temperature of the model with high fire source power is larger than that of the model with small fire source power, which is determined by the sensitivity of the flame action.

Two types of temperature slices are generally symmetrically distributed along the center line because the fire source is located in the center at ground level and the building space is symmetric along the $x$ and $y$ axes. A temperature cloud chart from the two sections with the highest air temperatures during the fire was selected for analysis.

When the fire source is in the center at ground level and the maximum fire source power is $20 \mathrm{MW}$, as shown in Figure 8, the temperature of the area where the fire source is located is the highest during the entire process of combustion. In the development phase of the fire (0-650 s), the fire source power increases parabolically, the height of the flame gradually increases, and flame radiation and hot smoke slowly rise to the center of the roof. In the central area, hot flue gas rises up to the roof due to air buoyancy, and it spreads to surrounding areas due to the blocking effect of the roof; therefore, the temperature on the roof rises faster than in other areas. In the stationary phase (600-2400 s), the fire source power reaches its maximum value and then remains the same. The temperature at the center of the roof reaches its peak value and fluctuates due to the instantaneous change in the flame height; however, the fluctuations are not large. The hot flue gas generated during continuous combustion continuously flows. It spreads along the edge of the roof to the surrounding wall. Finally, the temperature of the air under the roof gradually rises, and there is a clear temperature gradient between the roof and the area below. The temperature on the roof above the smoke plume is basically the peak of the entire combustion process (about $600{ }^{\circ} \mathrm{C}$ ). When the fire reaches $2400 \mathrm{~s}$, the hot smoke layer is thicker, and the air temperature at heights above $3 \mathrm{~m}$ from the ground generally surpasses $300{ }^{\circ} \mathrm{C}$. In the fire recession phase (2400-3600 s), the flame height decreases, with a gradual decrease in the fire source power. The cooling density of the hot flue gas increases and begins to sink. The air near 
the roof is less affected by the hot flue gas and flame radiation energy, and the temperature below the roof begins to decrease, gradually becomes uniform, and finally drops to about $60^{\circ} \mathrm{C}$.

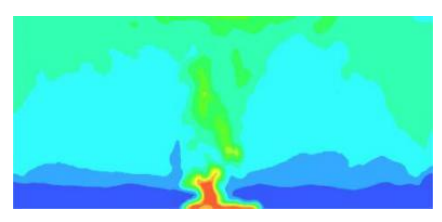

600 s

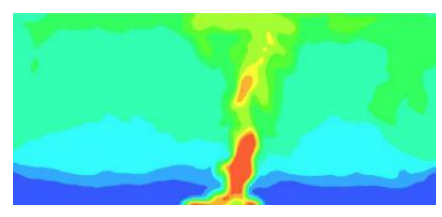

$2400 \mathrm{~s}$

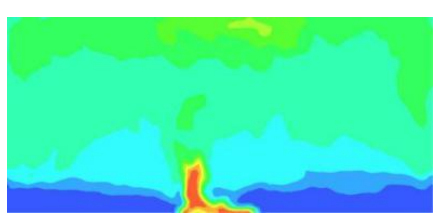

1200 s

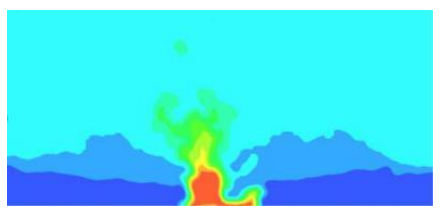

$3000 \mathrm{~s}$

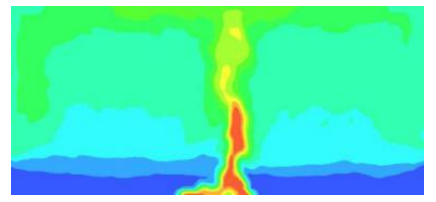

$1800 \mathrm{~s}$

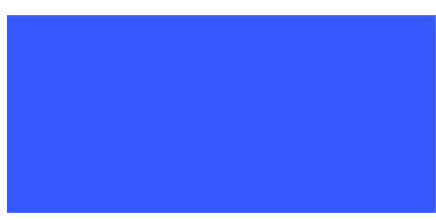

$3600 \mathrm{~s}$

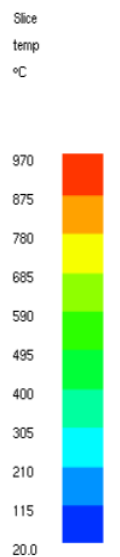

Figure 8. Slice temperature cloud (fire source location I).

\subsection{Fire Source Location II}

The temperature of each measuring point is shown in Figure 3. The development trend of the air heating curve is consistent with the fire source being at the center, and the trend is the same as that of the fire source power curve. The temperature of measuring point $C$, which is directly above the fire source, is much higher than at the other two points outside the fire source. The temperature at point $A$ is higher than at point $B$ because of the flow characteristics of hot flue gas (which we will not describe here). Observing the three measuring points, it can be seen that the temperature decreases with an increase in distance from the fire source.

On the other hand, the heating rate develops rapidly and the peak temperature value is large. As shown in Figure 9, the peak temperature at point $C$ is higher than at points $A$ and $B$. The heating rate at point $C$ is the fastest, while at point $A$ it is faster than at point $B$.

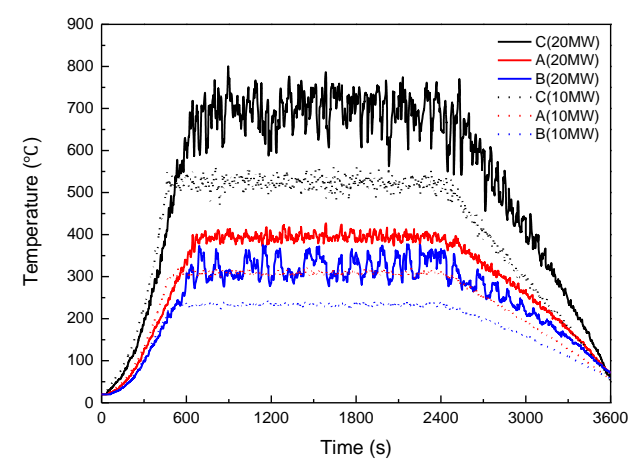

Figure 9. Air temperature at each monitoring point.

Figure 10 shows the temperature cloud of the cylindrical reticulated shell when the fire source is at the midpoint of the longitudinal side and the fire source power is at aximum, $20 \mathrm{MW}$. As the fire develops, the source power gradually becomes larger and the height of the flame slowly increases. The flame radiation has a greater influence on the air temperature on the roof above the fire source, which can reach $720^{\circ} \mathrm{C}$. Therefore, the temperature on the roof above the fire source is significantly higher than around the fire source. In the development stage of fire, hot flue gas reaches the roof directly above the fire source and is blocked from spreading to the longitudinal sides and, therefore, accumulating. Then it sinks, which drives the temperature rise on the roof. At $600 \mathrm{~s}$, the slicing temperature is stratified. When the fire reaches its peak value, the temperature stratification 
phenomenon is more obvious and remains in a relatively stable state. Since the temperature stratification phenomenon is mainly affected by flame radiation and the flow of hot flue gas, the maximum power of the fire source is gradually reduced in the declining stages of the fire. The height of the flames and the rate of the flow of hot flue gas decrease, which leads to a reduction in the temperature on the roof and the weakening of the stratification phenomenon.

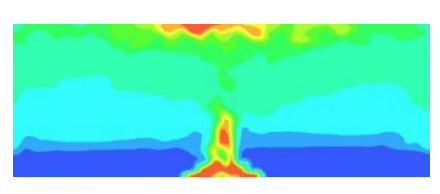

600 s

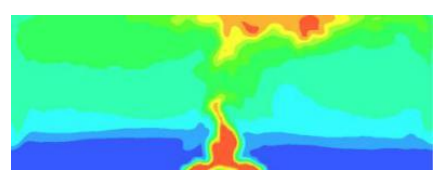

$2400 \mathrm{~s}$

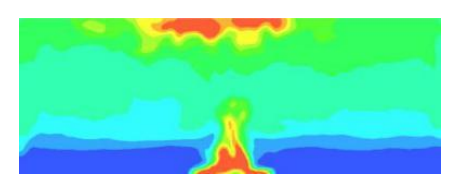

1200 s

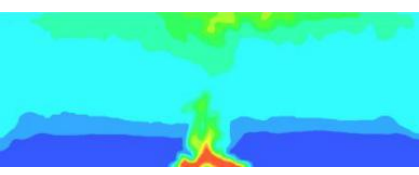

3000 s

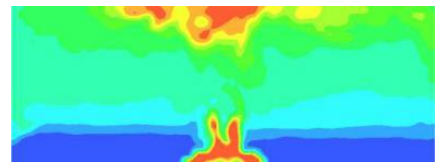

1800 s

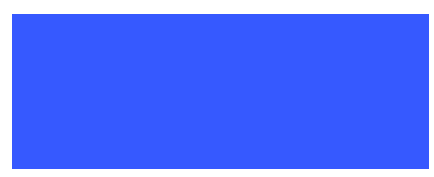

$3600 s$

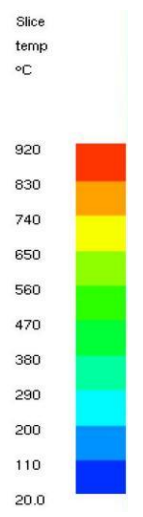

20.0

Figure 10. Slice temperature cloud (fire source location II).

As shown in Figure 10, during the fire development phase, flames increase in height and climb up the wall. At $600 \mathrm{~s}$, the flames have now climbed along the longitudinal wall to the roof, which drives the air temperature higher on the roof above the fire source. When the fire plume reaches the edge of the roof, it quickly develops along the longitudinal side of the roof and spreads along the top of the roof. It spreads along the longitudinal side to the gables on both sides and to the roof at the top. Then it moves along the roof away from the fire source due to pressure from fresh, hot smoke. It develops in a downward direction and fills the upper area after being blocked. Therefore, the air temperature in the upper area is higher than in the lower area. At the peak stage of the fire, the highest temperature of the slice reaches $900{ }^{\circ} \mathrm{C}$ or higher. At this point, the slice has a significant temperature gradient and the temperature field enters a steady state until the fire source decays.

\subsection{Fire Source Location III}

Figure 11 shows the position of the measuring points. The temperature curve of the testing points at the corner of the fire source is illustrated in Figure 12. The temperature of point D, which is directly above the fire source, is much higher than at the other measuring points. The temperatures of the other three measuring points are as follows: point $B>$ point $A>$ point $C$. Point $B$ is located at the highest point on the roof near the gable, which is close to the fire source. Here, hot smoke can easily reach the roof and spread along the intersection of the roof and the gable. Therefore, the temperature here is the second highest, only lower than at point $\mathrm{D}$, which is directly above the fire source. Point $\mathrm{A}$ is farther away from the fire source than is point $C$; however, the temperature here is higher. The reason is that the fire source is located in the corner by the wall, so hot flue gas with a high temperature (generated by combustion) can easily spread along the height of the roof and concentrate at the top of the roof. 


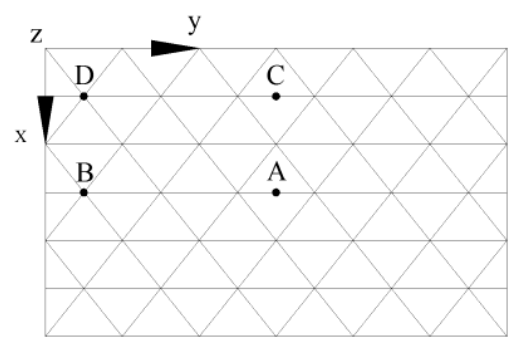

Figure 11. Part of the measurement points.

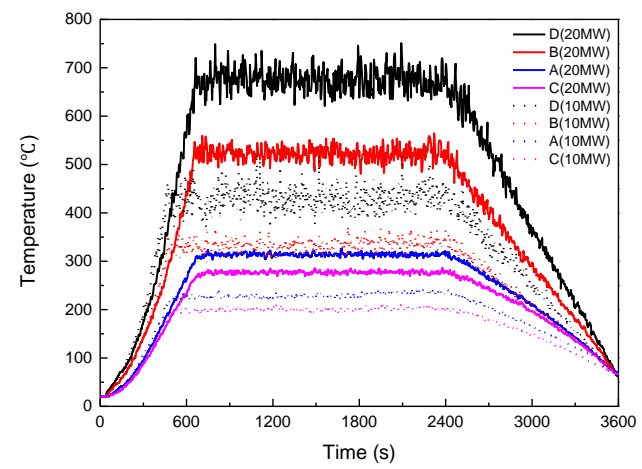

Figure 12. Air temperature at each monitoring point.

When the fire source is in the corner with a maximum fire source power of $20 \mathrm{MW}$, the distribution of the fire temperature field and the law of flue gas flow are very different than they are when the fire source is at the center. Because the location of the fire source is close to the roof and near the gable, the fire flame spreads along the intersection of the roof and the gable to the roof directly above the fire source, due to the increased power of the fire source, which causes the temperature to rise rapidly and form a gradient between this area and the temperature in areas further from the fire source. The hot flue gas first spreads along the upper roof and quickly flows to the other side of the gable. When it encounters the barrier, it develops in a downward direction. At the peak stage of the fire, the hot flue gas is continuously generated, which keeps the air temperature field relatively stable. At 1200-2400 s, the high-temperature region, which is over $300^{\circ} \mathrm{C}$, covers over half of the entire space. If the fire lasts until $3600 \mathrm{~s}$, the slice temperature is reduced by $50^{\circ} \mathrm{C}$ everywhere and is distributed evenly.

Figure 13 illustrates the slice temperature results when the maximum fire source power is $20 \mathrm{MW}$. In the early stage of the fire, the flame continues to rise up to the roof above the fire source, and then spreads along the wall in a longitudinal direction and along the roof up to the top of the roof. The difference between this and the fire source at the midpoint of the longitudinal side is due to the blocking effect of the gable. The flame can only spread to one side along the roof on the longitudinal side and, thus, more fire plumes can laterally develop near the gable and across the apex of the roof. At this point, the temperature near the roof at $y=2.5 \mathrm{~m}$ is much higher. During the decay phase of the fire, the temperature of the flue gas decreases with an increase in density. It sinks slowly under the effect of its own weight. When the fire reaches $3600 \mathrm{~s}$, the slicing temperature tends to become uniform.

In summary, the distribution of air temperature field in large space buildings is regional and layered, which is different from the uniformity of indoor fire temperature field in steel frame buildings. The change of the position of fire source affects the distribution of air temperature field, especially the distribution of high temperature area. When the fire source is located in the middle of the longitudinal side and the corner, the temperature of the area directly above the fire source is the highest, which is above $700{ }^{\circ} \mathrm{C}$. The high temperature of the local area is not conducive to the overall fire resistance of the structure; therefore, the occurrence of such fire should be avoided as much as possible. 


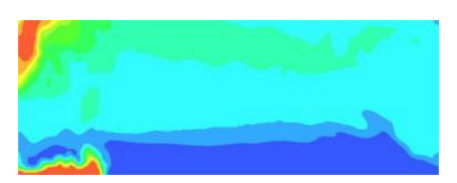

$600 \mathrm{~s}$

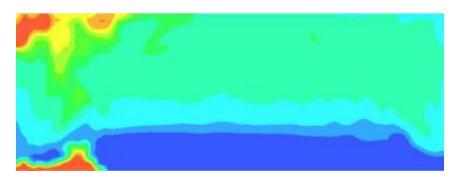

2400s

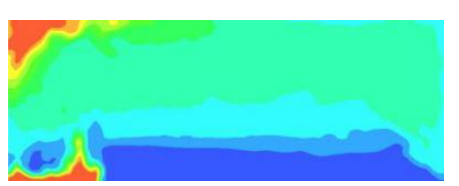

1200 s

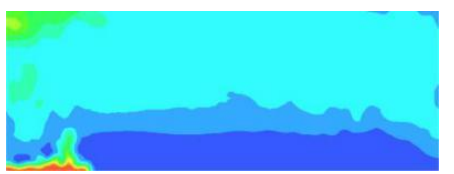

$3000 s$

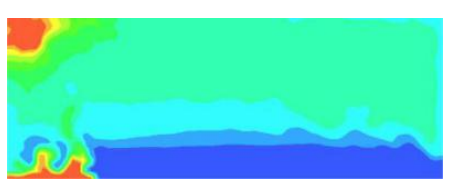

1800 s

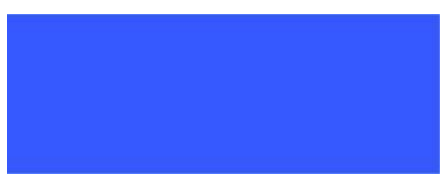

3600 s

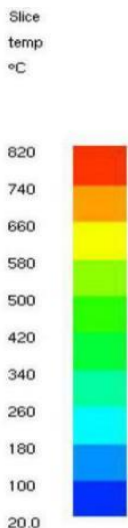

Figure 13. Slice temperature cloud (fire source location III).

\section{Fire Temperature Field Analysis of the Cylindrical Latticed Shells}

\subsection{Temperature Calculation of the Steel Members}

Latticed shells are comprised of thin-walled circular steel tubes with a high $F / V$, which causes the heat transferred to the steel members in and around the same section to, basically, be the same. It is assumed that the temperature of each point in the same cross section of the steel members is the same without the consideration of the heat conduction inside the members. Therefore, the temperature rise of the steel members can be calculated by simplified calculation method proposed in the Chinese Code: the Technical specifications for the fire protection of steel structures in buildings [21]. For the light steel members with uniform temperature distribution, the iterative method is widely used in the calculation of temperature rise. The iterative calculations for the temperature of steel members are carried out by Equations (4)-(7):

$$
\begin{gathered}
T_{S}(t+\Delta t)=K \cdot \frac{1}{\rho_{s} \cdot c_{s}} \cdot \frac{F}{V}\left[T_{g}(t)-T_{S}(t)\right] \cdot \Delta t+T_{S}(t) \\
\Delta T_{S(t, t+\Delta t)}=K \cdot \frac{1}{\rho_{s} \cdot c_{S}} \cdot \frac{F}{V}\left[T_{g}(t)-T_{S}(t)\right] \cdot \Delta t \\
K=\alpha_{r}+\alpha_{\mathcal{c}} \\
\alpha_{r}=\frac{\varepsilon_{r} \cdot 5.67 \times 10^{-8}}{T_{g}-T_{S}} \cdot\left[\left(T_{g}+273\right)^{4}-\left(T_{S}+273\right)^{4}\right]
\end{gathered}
$$

where $T_{S}$ is the temperature of the steel tubes in the latticed shells $\left({ }^{\circ} \mathrm{C}\right) ; \Delta T_{S}$ is the temperature increment in the steel tubes $\left({ }^{\circ} \mathrm{C}\right) ; T_{g}$ is the air temperature around the steel tubes in the latticed shells $\left({ }^{\circ} \mathrm{C}\right) ; \Delta t$ is the time step, which is $5 \mathrm{~s}$ in this paper; $K$ is the heat transfer coefficient $\left(\mathrm{W} /\left(\mathrm{m} \cdot{ }^{\circ} \mathrm{C}\right)\right) ; \rho_{s}$ is the density of steel $\left(7850 \mathrm{~kg} / \mathrm{m}^{3}\right) ; C s$ is the specific heat capacity of steel $\left(600 \mathrm{~J} /\left(\mathrm{kg} \cdot{ }^{\circ} \mathrm{C}\right)\right) ; F$ is the area of the steel tube units exposed to fire $\left(\mathrm{m}^{2} / \mathrm{m}\right) ; V$ is the volume of the steel tube units exposed to fire $\left(\mathrm{m}^{3} / \mathrm{m}\right) ; F / V$ is section shape coefficient $\left(\mathrm{m}^{-1}\right) ; \alpha_{c}$ is the radiation heat transfer coefficient; $\varepsilon_{r}$ is the overall heat radiance, where $\varepsilon_{r}=0.5$; and $\alpha_{c}$ is the convective heat transfer coefficient, where $\alpha_{c}=25 \mathrm{~W} /\left(\mathrm{m}^{2}{ }^{\circ} \mathrm{C}\right)$.

We calculated the air temperature of the latticed shell near the steel pipe tubes in different fire scenarios using FDS. Iterative calculations of the temperature of the steel tubes were carried out through the MATLAB program, which was written based on the simplified calculation method presented above.

\subsection{Temperature Field of Cylindrical Latticed Shells}

The flame from fuel combustion produces a heat radiation effect on steel components. The hot flue gas generated by combustion produces a heat convection effect. Under the effect of heat radiation and convection, the temperature of the steel components rises and the heat transfer process reaches a steady state. Because the steel tube components of the reticulated structure are made of light steel, 
the iterative calculations were carried out to obtain the temperature field of the reticulated shells in a fire. This paper used MATLAB programming calculations to convert the air temperature into the temperature of the steel components. The initial temperature of the steel component was set to $20^{\circ} \mathrm{C}$. The time step was set to $2 \mathrm{~s}$. The radiation heat transfer coefficient was $25 \mathrm{~W} /\left(\mathrm{m}^{2} \cdot{ }^{\circ} \mathrm{C}\right)$ according to the fire conditions. It can be seen that there was a certain energy loss in the process of temperature transfer from the air to the rod. However, because of the good thermal conductivity of the steel and the large section coefficient of the round steel tube (F/V, as shown in Equation (8)), the temperature of the steel component is not that different from the air temperature. The difference decreases with an increase in the temperature. At the same time, it can be seen from Table 3 that the thickness of the steel pipes has more of an influence on the temperature rise of the steel component. The temperature increases more slowly with thicker steel pipes. Equation (8) is

$$
F / V=d /[t \times(d-t)]
$$

where $d$ refers to the diameter of the round steel tubes, and $t$ refers to the thickness of the round steel tubes.

Table 3. Bar section coefficient.

\begin{tabular}{cccc}
\hline Pipes & $\Phi 60 \times 3$ & $\Phi 110 \times 3$ & $\Phi 60 \times 6$ \\
\hline Section Coefficient $F / V$ & 350.877193 & 342.6791277 & 185.1851852 \\
\hline
\end{tabular}

Note: (1) When $F / V<10$, the component temperature should be calculated according to the nonuniform distribution of the section temperature. (2) When $F / V>300$, the component temperature is considered to be equal to the air temperature.

\section{Structural Response Analysis in Different Fire Scenarios}

\subsection{Structural Model}

A three-way grid and a single-layer cylindrical reticulated shell were selected for the analytical model, as shown in Figure 1. The cylindrical reticulated shell is installed directly onto the ground by pin. The length of the reticulated shell is $24 \mathrm{~m}(l=24 \mathrm{~m})$, which is divided into six grids. Each grid length is $4 \mathrm{~m}$. The span $(b=15 \mathrm{~m})$ is divided into six grids along the direction of the span, in accordance with the principle of equal arc length. The long-span ratio of the reticulated shell is 1.6, and the rise-span ratio is $1 / 2,1 / 3$, or $1 / 4$. The roof loads are $1.8 \mathrm{kN} / \mathrm{m}^{2}, 1.2 \mathrm{kN} / \mathrm{m}^{2}$, and $0.6 \mathrm{kN} / \mathrm{m}^{2}$. The parameters of the model analyzing the single-layer cylindrical reticulated shell structure are shown in Table 4.

The key nodes and elements of the reticulated shell were analyzed to verify the displacement and internal force of the structure due to different fire source positions and different maximum fire source power values, as shown in Figure 14. The vertical displacement time of key nodes and the internal force of the elements were compared under different conditions.

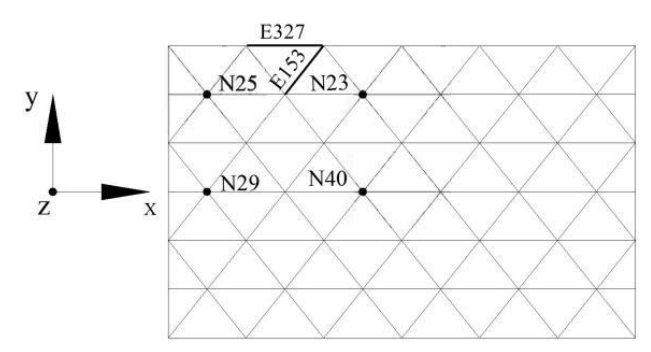

Figure 14. Key nodes and elements of the analytical model. 
Table 4. Parameters of single-layer cylindrical reticulated shell.

\begin{tabular}{|c|c|c|c|c|c|}
\hline $\begin{array}{l}\text { Fire Source } \\
\text { Location }\end{array}$ & $\begin{array}{l}Q_{\max } \\
\text { (MW) }\end{array}$ & $\begin{array}{l}\text { Rise-Span } \\
\text { Ratio }\end{array}$ & $\begin{array}{l}\text { Member Sections } \\
(\mathrm{mm})\end{array}$ & $\begin{array}{l}\text { Roof Load } \\
\left(\mathrm{kN} / \mathrm{m}^{2}\right)\end{array}$ & $\begin{array}{l}\text { Thickness } \\
(\mathrm{mm})\end{array}$ \\
\hline I & \multirow{3}{*}{20} & $1 / 2$ & $\Phi 110 \times 4, \Phi 54 \times 4, \Phi 110 \times 4, \Phi 57 \times 4^{\prime}$ & 0.6 & $\mathrm{Di}=1$ \\
\hline II & & $1 / 3$ & $\Phi 110 \times 4, \Phi 60 \times 4, \Phi 108 \times 4, \Phi 60 \times 4$ & 1.2 & $\mathrm{Di}=2$ \\
\hline III & & $1 / 4$ & $\begin{array}{c}\Phi 106 \times 4, \Phi 60 \times 4, \Phi 146 \times 5, \Phi 76 \times 4 \\
\Phi 114 \times 4, \Phi 102 \times 4, \Phi 114 \times 4, \Phi 102 \times 3.5\end{array}$ & 1.8 & $\mathrm{Di}=3$ \\
\hline
\end{tabular}

\subsubsection{Element Model}

Steel tubular sections are commonly selected to be the members of the reticular dome. Element B31 in ABAQUS is adapted to simulate the tubular pipes of the cylindrical latticed shell. Three-dimensional beams have six degrees of freedom at each node including three translational degrees of freedom and three rotational degrees of freedom. The stress components in three-dimensional, shear-deformable beam elements are the axial stress and the shear stress due to torsion. All steel components of the reticulated shell structure are steel tubes (Q235). The cross sections of the steel tube are selected by the static stability analysis, which were selected to be $\Phi 110 \times 4$ and $\Phi 57 \times 4, \Phi 146 \times 5$ and $\Phi 76 \times 4$, and $\Phi 114 \times 4$ and $\Phi 102 \times 4$ as shown in Table 3. There are eight integral points on the cross section of PIPE beam element as shown in Figure 15.

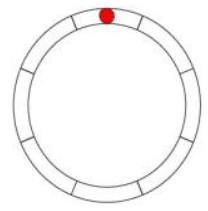

$1 \mathrm{P}$

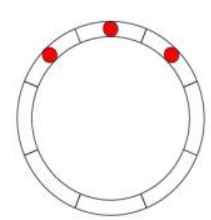

$3 P$

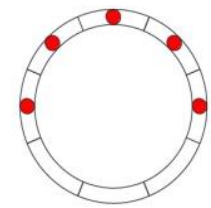

$5 \mathrm{P}$

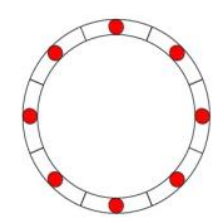

$8 \mathrm{P}$

Figure 15. Integral points of the steel tubular members.

\subsubsection{Material Properties}

In order to investigate the behaviors of the cylindrical latticed shell under different temperatures, it is necessary to define the material properties changing with temperature including the coefficient of thermal expansion, elasticity modulus, yield strength, and stress-strain relationship. According to the Chinese Technical Code for Fire Safety of Steel Structure in Buildings (CECS200) [21], the material properties used in this paper are illustrated as follows.

\section{- $\quad$ Elasticity modulus}

The elasticity modulus decreases with the increase of temperature. Along with the decrease of the elasticity modulus, the structural deformation will gradually increase until it reaches the limit state and bearing capacity. The reduction coefficient $\psi_{T}$ of elastic modulus is defined as the ratio of the elasticity modulus at high temperature $\mathrm{T}^{\circ} \mathrm{C}$ to the elasticity modulus at room temperature, which is shown as $\psi_{T}=E_{T} / E$.

In this paper, the reduction coefficient of elastic modulus of steel at high temperature is selected according to CECS200 shown as Equations (9).

$$
\begin{cases}\psi_{T}=\frac{7 T_{s}-4780}{6 T_{s}-4760}, & 20^{\circ} \mathrm{C} \leq T_{s}<600^{\circ} \mathrm{C} \\ \psi_{T}=\frac{1000-T_{s}}{6 T_{s}-2800}, & 600^{\circ} \mathrm{C} \leq T_{s} \leq 1000^{\circ} \mathrm{C}\end{cases}
$$

- Yield strength 
The reduction coefficient $\eta_{T}$ of yield strength is defined as the ratio of the yield strength at high temperature $\mathrm{T}^{\circ} \mathrm{C}$ to the yield strength at room temperature, which is $\eta_{T}=f_{y T} / f_{y}$ as Equation (10).

$$
\begin{aligned}
\eta_{T} & =1.0,20^{\circ} \mathrm{C} \leq T_{S}<300{ }^{\circ} \mathrm{C} \\
\eta_{T} & =1.24 \times 10^{-8} T_{S}{ }^{3}-2.096 \times 10^{-5} T_{S}{ }^{2}+9.228 \times 10^{-3} T_{S}-0.2168,300^{\circ} \mathrm{C} \leq T_{S}<800{ }^{\circ} \mathrm{C} \\
\eta_{T} & =0.5-T_{S} / 2000,800^{\circ} \mathrm{C} \leq T_{S} \leq 1000^{\circ} \mathrm{C}
\end{aligned}
$$

\section{- Constitutive model}

The stress-strain relationship of steel at high temperature is investigated by scholars globally. Based on the European standard EC3 [22], the constitutive model at high temperature without considering post yield strengthening is utilized in this paper. The stress-strain relationship model of steel at different temperatures prescribed in EC3 is shown in Figure 16.

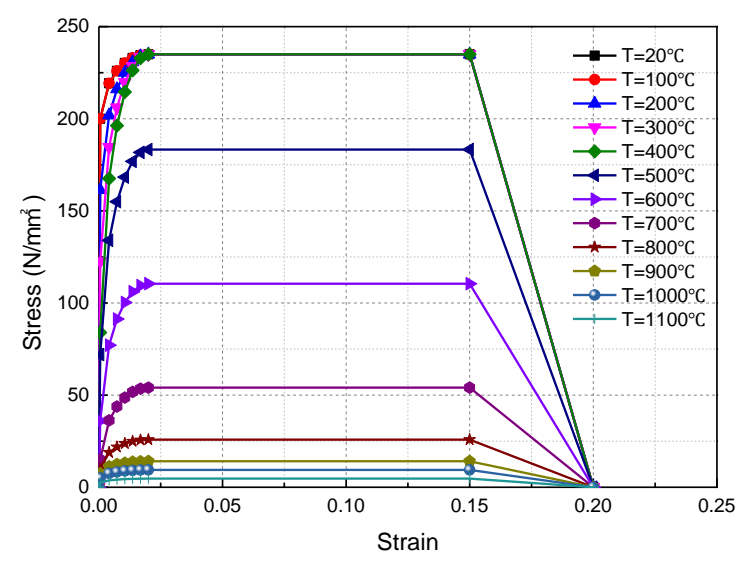

Figure 16. Stress-strain relationship model of steel at high temperatures prescribed in EC3.

- $\quad$ Physical properties

Material physical properties including density, heat capacity, coefficient of thermal expansion and coefficient of thermal conductivity are determined according to CECS200. Because the change of temperature has little effect on the density of steel, the density $\rho_{s}$ is $7580 \mathrm{~kg} / \mathrm{m}^{3}$. The heat capacity $C_{s}$ is $600 \mathrm{~J} /\left(\mathrm{kg} \cdot{ }^{\circ} \mathrm{C}\right)$. The coefficient of thermal expansion is used to express the volume change caused by the change of unit temperature. The coefficient of thermal expansion refers to the ratio of the elongation and the original length when the temperature of steel member changes by $1{ }^{\circ} \mathrm{C}$. Thermal expansion coefficient $\alpha_{s}$ is $1.2 \times 10^{-5}$. The thermal conductivity of material is one of the important physical properties. The coefficient of thermal conductivity refers to the ability of material to conduct heat directly, which is the heat transferred per unit area in unit time when unit temperature is increased. The coefficient of thermal conductivity $\lambda$ is $45 \mathrm{~W} /\left(\mathrm{m} \cdot{ }^{\circ} \mathrm{C}\right)$.

\subsection{Displacement Analysis of the Cylindrical Latticed Shell}

Figures 17-19 show a displacement cloud diagram of a structure during a fire, with different fire source locations.

When the maximum fire source power is $20 \mathrm{MW}$, the structure has different failure modes and fire durations depending on the location of the fire source. The maximum displacement point of the reticulated shell under a normal temperature load is located at the highest midpoint of the roof. The equivalent displacement is $0.09 \mathrm{~m}$. The structure remains in an overall stable state. When the fire source is in the center at the ground level, as shown in Figure 17, the structure remains basically stable during the first $1860 \mathrm{~s}$ of the fire. At $1863 \mathrm{~s}$, the components on the left side yield first, and then the upper reticulated structure begins to collapse from the middle. After a few seconds, the cylindrical 
reticulated shell collapses completely at $1866 \mathrm{~s}$, while the maximum displacement of the node in the middle of the roof is up to $11.63 \mathrm{~m}$. The structure reaches its bearing capacity limit at $1863 \mathrm{~s}$, and the structure is completely destroyed. The fire resistance limit of the structure in these fire conditions is thus $1863 \mathrm{~s}$. When the fire source is set at the midpoint of the longitudinal side, as shown in Figure 18, the structure remains stable during the first $580 \mathrm{~s}$. The steel pipes on the side near the fire source yield first, at $583 \mathrm{~s}$. As the temperature continues to rise, the steel pipes on the right side of the reticulated shell (above the fire source) collapse entirely. At $586 \mathrm{~s}$, they basically completely collapsed. At this point, the maximum displacement of the top node of the reticulated shell is $11.82 \mathrm{~m}$. The structure loses its bearing capacity at a fire duration of $583 \mathrm{~s}$. When the fire source is in the corner, as shown in Figure 19, the steel pipes on the right side of the roof begin to become destabilized at 569 s. At 570 s, the steel pipes on the right side of the roof start to extensively collapse. The reticulated shell completely collapses at $572 \mathrm{~s}$. At this point, the structure is completely destroyed, with the maximum displacement of the middle roof node at $11.59 \mathrm{~m}$. The fire resistance of the reticulated shell is thus $569 \mathrm{~s}$. Comparing the three fire scenarios above, it was found that the maximum nodal displacement of the reticulated shell was basically the same with the different fire scenarios. The fire resistance limit of the reticulated shell was the largest at $1863 \mathrm{~s}$, when the fire source was at the center at ground level. When the fire source was at the midpoint or in the corner of the longitudinal side, the reticulated shell was destroyed at the beginning of the fire. The fire resistance limit of the reticulated shell reduced by $70 \%$. In the actual design, attention should be paid to the placement of combustibles to avoid fires starting from the close areas of the two fire scenarios.
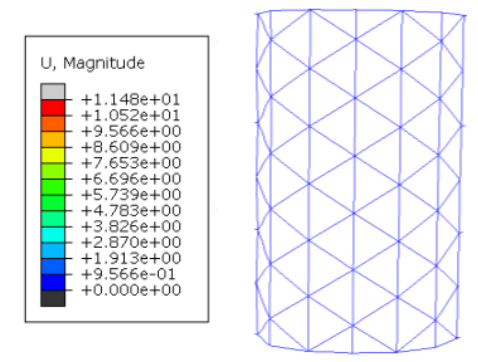

$1863 \mathrm{~s}$

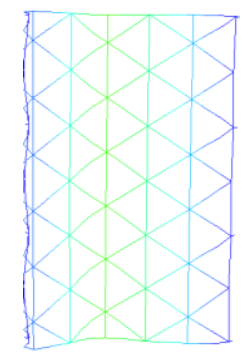

$1864 s$

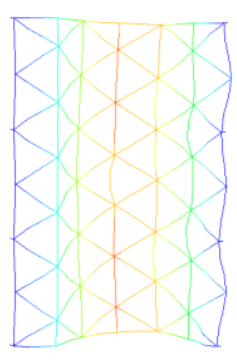

$1865 \mathrm{~s}$

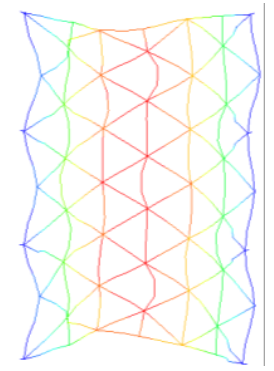

$1866 s$

Figure 17. Structural deformation under fire location I.

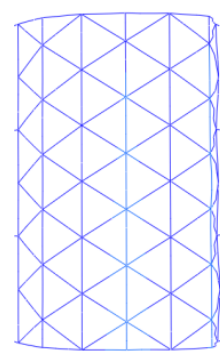

583s

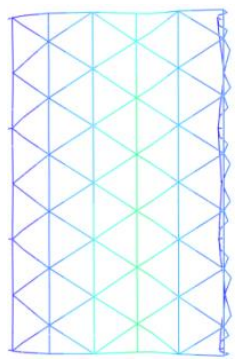

584 s

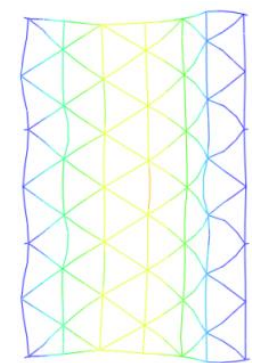

$585 s$

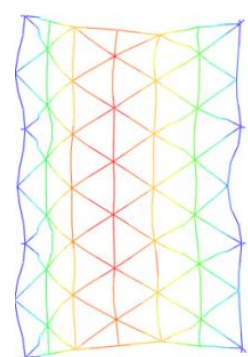

586s

Figure 18. Structural deformation under fire location II. 


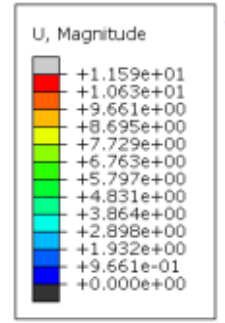

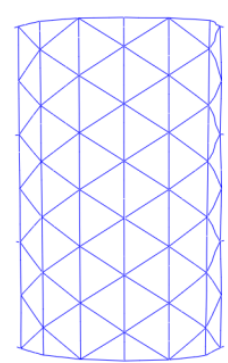

$569 \mathrm{~s}$

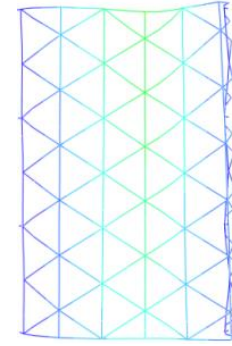

$570 \mathrm{~s}$

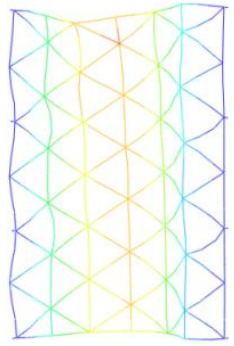

$571.4 \mathrm{~s}$

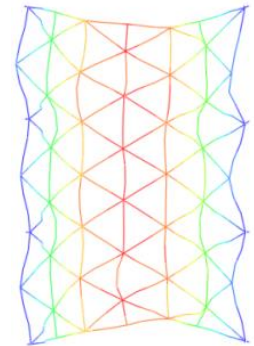

$572 \mathrm{~s}$

Figure 19. Structural deformation under fire location III.

Figure 20 shows the displacement of selected key nodes in different fire source conditions. It can be seen that with self-weight, the midspan nodes $\mathrm{N} 40$ and $\mathrm{N} 29$ produce an initial downward displacement of $0.1 \mathrm{~m}$. The nodes $\mathrm{N} 23$ and N25, near the longitudinal side, have an initial upward displacement of $0.032 \mathrm{~m}$. The midspan nodes produce an initial downward displacement. The nodes close to the longitudinal side have an initial upward displacement. In the meantime, the structure presents a different displacement response with a different fire source power, which is caused by the rapid decrease in the elastic modulus of the steel at temperatures above $400^{\circ} \mathrm{C}$. During a fire in a cylindrical reticulated shell, when the maximum fire source power is $20 \mathrm{MW}$ and there are different fire source positions, the limits of the bearing capacity are reached in the stationary phase or during the rising phase of the fire. It can be seen from Figure 20a that the thermal expansion of structural members causes upward displacement of nodes with the rise of temperature in 0-650 s. The thermal expansion is the main factor of structural deformation. In 650-1350 s, the temperature of the members is relatively stable and basically lower than $500{ }^{\circ} \mathrm{C}$. The elasticity modulus of the members reached to $75 \%$ of the elasticity modulus of steel. The yield strength is basically not reduced and the displacement of the node remains relatively stable. In 1350-1863 s, when the temperature is over $500{ }^{\circ} \mathrm{C}$, the elastic modulus and yield strength of the steel are reduced by $50 \%$. The internal forces of the structure redistributes at $1863 \mathrm{~s}$. The steel members enter into the plastic state. The node displacement suddenly increases to $1.0 \mathrm{~m}$ at $1863 \mathrm{~s}$. The reticulated shell structure reached to the limit state and lost its bearing capacity. Among the three fire scenarios, the local temperature rise caused by the fire source being in the corner makes the structure the most dangerous. In the fire development stage, each node produces an upward displacement due to the thermal expansion effect of the steel structure, which is caused by the heating of the roof. The thermal expansion effect increases with a decrease in the distance to the fire source. The displacement value increases with an increase in the upward displacement of the joint. During the stationary stage of the fire, each node reaches maximum displacement and remains in a relatively stable interval. Then the fire source declines slowly, and thermal expansion weakens with each node slowly returning to its original place. Throughout the entire fire process, the node's maximum displacement never reaches the limits specified by the failure criteria. The entire structure remains stable. In the meantime, thermal expansion of the pipes causes the upward displacement of the components due to the effects of gravity load. Therefore, the deflection of the structure under a load is smaller than at normal temperatures, which is beneficial to structural stress in the initial stages of a fire. 


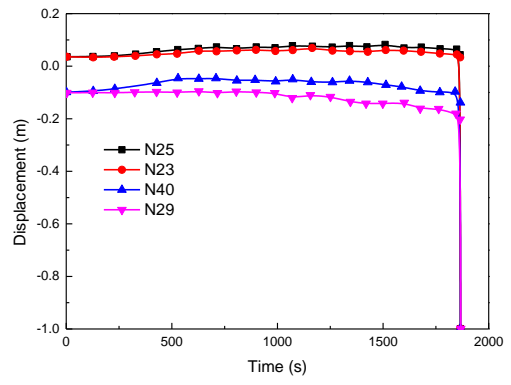

(a)

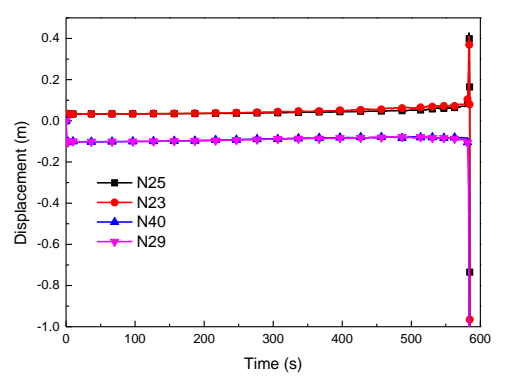

(b)

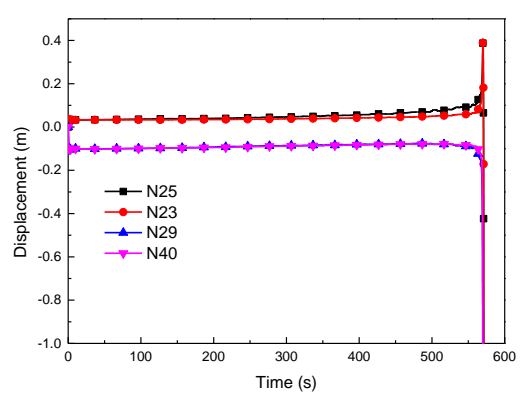

(c)

Figure 20. Time-history curves of displacement of key nodes in different fire conditions. (a) Fire location I; (b) fire location II; (c) fire location III.

\subsection{Internal Forces Analysis of the Cylindrical Latticed Shell}

When the maximum fire source power is $20 \mathrm{MW}$, this greatly influences the reticulated shells, which leads to the reticulated shell collapsing before the end of the fire. The axial force diagram of the structural component before the collapse is shown in Figure 21. Due to the thermal expansion of the steel, the secondary pipes along the longitudinal side basically become the pipes with the largest pull force. When the fire source is at the midpoint or in the corner, the maximum axial force of the pipe members in the critical state is larger than it is if the fire source is in the center at ground level.

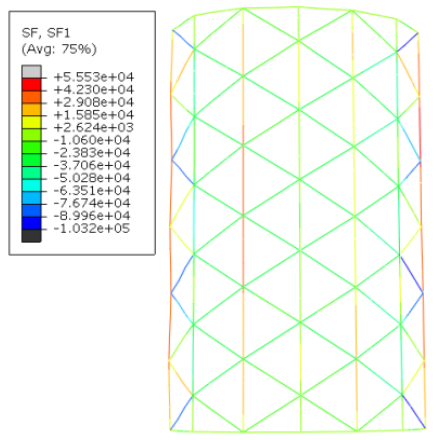

(a)

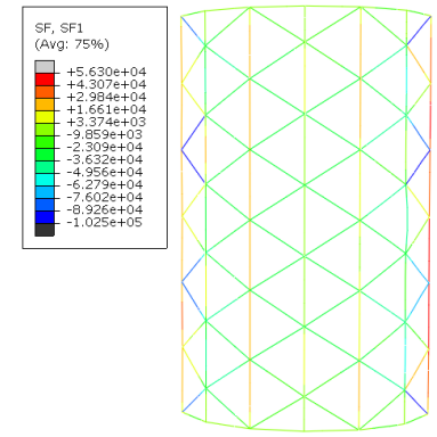

(b)

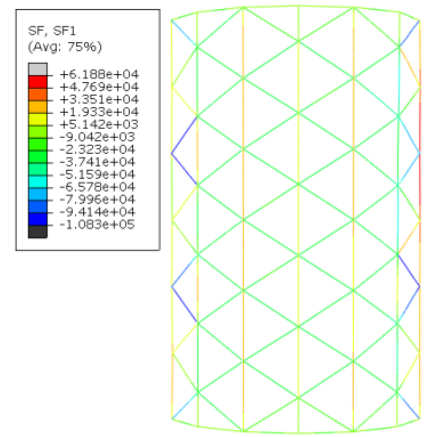

(c)

Figure 21. The axial force of the structure in different fire conditions. (a) Fire location I (1863s); (b) fire location II (582s); (c) fire location III (567s).

Pipes E153 and E327 were selected for analysis, using the largest axial force under each working condition, as shown in Figure 22. In the development stage of the fire, the structure arches in an upward direction due to thermal expansion. Therefore, the pipes bear tension. The axial force of the tension for E327 increases in different fire source conditions. The axial force of compression of E153 is reduced. Therefore, in the initial stage of the fire, thermal expansion contributes to the overall bearing capacity of the reticulated shell. If the temperature does not increase at this time, the internal force of the pipe members remains in a stable state, and the structure can continue to bear loads during a fire, as shown in Figure 22. When the temperature reaches about $500^{\circ} \mathrm{C}$ at the beginning of the fire and continues to rise (the fire source is at locations II and III), the materials' mechanical properties are reduced due to the rapid increase in the temperature load. The pipes directly above the fire source enter a state of plasticity. Then the members become unstable because of the fire load. The internal forces of the entire structure are redistributed. Due to the increase in the number of pipes that are unstable, the cylindrical reticulated shell finally collapses. The axial force of pipes E153 and E327 instantaneously changes in direction. 


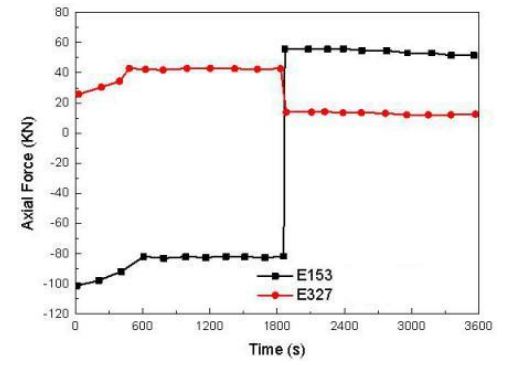

(a)

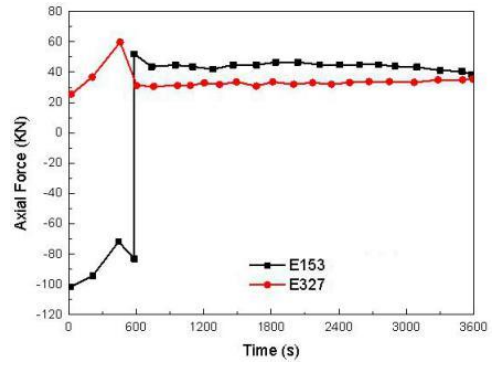

(b)

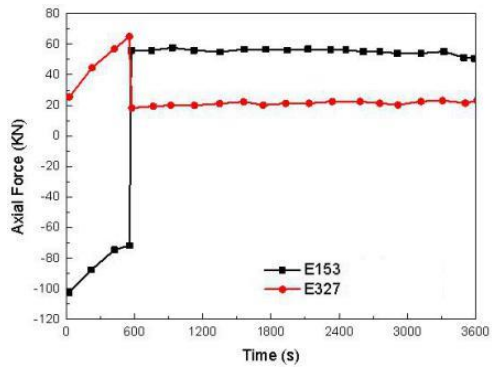

(c)

Figure 22. Time-history curves of axial force of key members in different fire conditions. (a) Fire location I (1863s); (b) fire location II (582s); (c) fire location III (567s).

\section{Effect of Structural Parameters on the Responses of Reticulated Shells During a Fire}

\subsection{Influence of Steel Dimensions}

The influences of the diameter of the steel tubes and wall thickness on the fire resistance of reticulated shells were studied using the following steel tube diameters and wall thicknesses. The fire source was located in the center of the ground. The maximum fire source power was $20 \mathrm{MW}$, and the rise-span ratio was $1 / 3$. The displacement of the N40 node (above the fire source) was selected to analyze whether the reticulated shell structure would lose its bearing capacity and the time at which the structure would reach its ultimate bearing capacity.

Figure 23 illustrates a comparison of time-history curves of the displacement of reticulated shells at the N40 node above the fire source, with different cross-sectional dimensions of the reticulated shells. The size of a cross-section has a major impact on the fire resistance of single-layer cylindrical reticulated shells. Pipes with large cross-sections are conducive to improving the fire resistance of the entire structure. It could be found that the fire resistance of the structure decreases with a decrease in the sectional dimensions of the pipes. This can effectively improve the fire resistance of the structure.

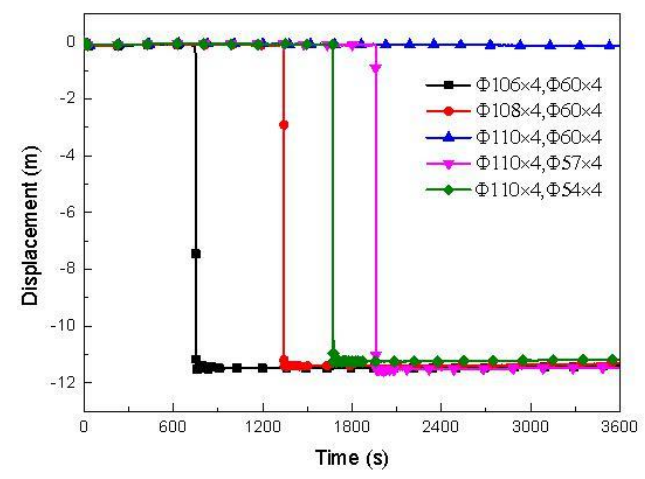

Figure 23. Time-history curve of vertical displacement (influence of the members).

\subsection{Influence of the Rise-Span Ratio}

The rise-span ratio not only affects the height of the latticed, reticulated shells, but also affects the air temperature field inside the structure. In this section, we examine what happens when the fire source is located in the center at ground level with a maximum fire source power of $20 \mathrm{MW}$ and a rise-span ratio of $1 / 2,1 / 3$, or $1 / 4$. We analyzed displacement in the N40 node above the fire source to investigate the influence of different rise-span ratios on the fire resistance performance of the latticed shell structure. A time-history curve of the vertical displacement of node N40 (above the fire source, with different rise-span ratios) is shown in Figure 24. 


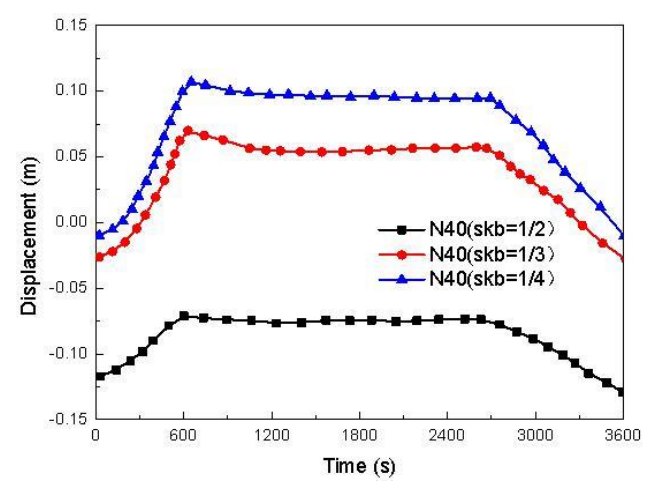

Figure 24. Time-history curve of vertical displacement (influence of the rise span ratio).

It can be seen that during a fire, the vertical displacement of the $\mathrm{N} 40$ node can be roughly divided into three processes. In the development stage of fire (0-650 s), the node temperature increases gradually, and the thermal expansion of steel at a high temperature makes the N40 node gradually produce upward displacement. When the fire is stable (650-2400 s), the displacement of the node remains stable at $2400 \mathrm{~s}$. The initial displacement of the system begins to decrease with a decrease in fire and thermal expansion. Because the maximum displacement of nodes during the fire does not exceed the limit of displacement of the shell $(0.5 \mathrm{~m})$, the reticulated shell does not fail and can continue to bear loads after the fire.

On the contrary, when the rise-span ratio is $1 / 2$, the initial vertical displacement of node N40 at a normal temperature is greater than $0.12 \mathrm{~m}$. The upward displacement of the node is the smallest. When the rise-span ratio is $1 / 4$, the vertical displacement of node $\mathrm{N} 40$ with a normal temperature loading is the smallest. However, in the fire development stage, the upward displacement of N40 increases rapidly, and the displacement value is large. When the rise-span ratio is $1 / 3$, the maximum displacement of node $\mathrm{N} 40$ is between the first two values. The reason is as follows: with a normal temperature load, the displacement value of node U3 in a reticulated shell structure with a large rise-span ratio is larger because of the large roof load.

In the meantime, during a fire from the same fire source, the lower the temperature of the node of the structural component with a large rise-span ratio is, the less obvious the thermal expansion effect of that component is. Therefore, in designing a latticed shell structure, the rise-span ratio should be selected to minimize the absolute value of displacement of the superstructure for the duration of a fire.

\subsection{Influence of Roof Load}

Three types of roof loads, $0.6 \mathrm{kN} / \mathrm{m}^{2}, 1.2 \mathrm{kN} / \mathrm{m}^{2}$, and $1.8 \mathrm{kN} / \mathrm{m}^{2}$, were compared to study the influence of latticed shell roof loads on fire resistance. The node displacement of N40, in the middle of the span, was selected to compare and analyze the influence of the roof load on the bearing capacity of the latticed shell structure during a fire.

A time-displacement curve for the N40 node in the middle span of a cylindrical reticulated shell with different roof loadings is shown in Figure 25. The maximum nodal displacement of the reticulated shell subjected to three types of roof loads is $0.02 \mathrm{~m}, 0.07 \mathrm{~m}$, and $0.24 \mathrm{~m}$, respectively. Through a comparison, it can be seen that the node displacement and the internal force increase with an increase in the roof load. The bearing capacity of the entire structure increases with a decrease in the roof load. The fire resistance limit of the reticulated shell increased by $50 \%$ with the decrease of the roof loads from 1.8 to $1.2 \mathrm{kN} / \mathrm{m}^{2}$. It can be seen that reducing the weight of the roof is conducive to fire resistance throughout the reticulated shell structure. Therefore, to ensure the safety and appearance of the structure, roof loads should be reduced to enhance the fire resistance of the structure. 


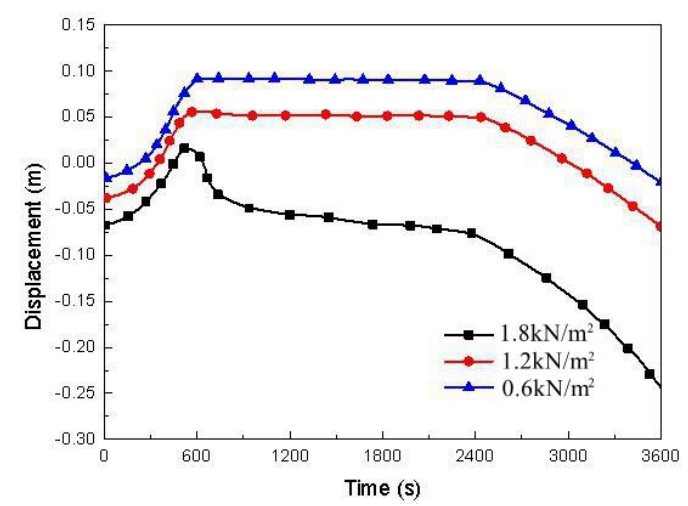

Figure 25. Time-history curve of vertical displacement (influence of the roof loads).

\subsection{Influence of Fireproof Coating}

The influence of the thickness of the fireproof coating on the fire resistance of a single-layer cylindrical latticed shell was studied by selecting thicknesses of $1.0 \mathrm{~mm}, 2.0 \mathrm{~mm}$, and $3.0 \mathrm{~mm}$, as shown in Figure 26. The temperature of steel with a fireproof coating was calculated using an iterative formula of temperature rise in steel with a protective layer. The influence of a fireproof coating was considered. Displacement at the midspan node was selected to compare and analyze the influence of the protective layer on the bearing capacity of the latticed shell structure during a fire. We determined whether latticed shell structures would lose their bearing capacity as well. It can be seen that in the early stages of fire, the displacement caused by thermal expansion decreases with an increase in the thickness of the protective layer. When the thickness of the fireproof coating is $0 \mathrm{~mm}$, the reticulated shell structure loses its bearing capacity in $726 \mathrm{~s}$. When a fireproof coating is added, the entire structure remains undamaged, and node displacement decreases with an increase in the thickness of the protective layer. When heat is transferred to the steel components through thermal radiation and convection, the fireproof coating absorbs part of the energy, slows down the speed of the flame and the heating rate of the components, reduces the temperature of the steel components through thermal radiation and convection, and improves the fire resistance of the steel components.

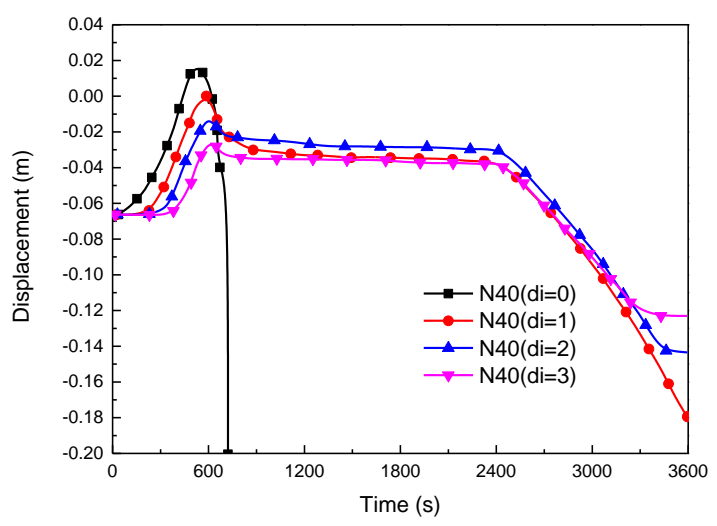

Figure 26. Time-history curve of vertical displacement (influence of fireproof coating).

\section{Conclusions}

This paper presents a comprehensive case analysis of the fire performance of single-layer cylindrical reticulated shells. Nonuniform fire temperature fields of single-layer cylindrical reticulated shells under different fire scenarios were generated using a Fire Dynamics Simulator (FDS). A performance-based analysis of single-layer cylindrical steel reticulated shells during a fire was carried out. The primary findings can be summarized as follows: 
1. This paper compared the FDS simulation and fire test results. It is can be seen that the numerical simulation and test results are relatively similar. Therefore, the accuracy and reliability of the simulation method can be verified.

2. The temperature field of the fire scenarios simulated by FDS shows that the space above the fire source area had the highest temperature, and gradually reduced for the spaces away from the fire source. The location of the fire source has considerable influence on the temperature field within the structures, especially the distribution of the high-temperature areas. The temperature field is non-uniform within the reticulated shell structure. For three different fire scenarios, the highest fire temperatures were above $600{ }^{\circ} \mathrm{C}$. The high temperature of this localized area is detrimental to the overall fire resistance of the structure.

3. Comparing the three fire conditions above, it can be concluded that the maximum nodal displacement of the reticulated shell was basically the same with the different fire conditions. The fire resistance limit of the structure decreases with an increase in fire source power. When the fire source was at the midpoint or in the corner of the longitudinal side, the reticulated shell was destroyed at the beginning of the fire. The fire resistance limit of the reticulated shell reduced by $70 \%$.

4. In order to enhance the fire resistance of large-span steel reticulated shells, the following suggestions are proposed: (a) increase the size of the members and the thicknesses of the protective layer of the tubes. (b) Reduce the roof loadings of the reticulated shells. (c) Avoid piling combustible goods near the corner of reticulated shells during service period of the structure.

5. This research presented a comprehensive demonstration to show how fire resistance of a large-span steel reticulated shells can be assessed based on performance-based fire design approach step-by-step. The information presented in this paper is useful for practical structural engineers for conducting the fire resistance design of complex large-span steel reticulated shells.

Author Contributions: Conceptualization, Z.Y. and C.L.; methodology, C.L.; investigation, Y.Z.; writing-review and editing, Z.Y. and Y.Z.; All authors have read and agreed to the published version of the manuscript.

Funding: This research is supported by the National Natural Science Foundation of China (51778157), the Guangzhou Civic Bureau of Education (1201581640) and the Foundation for Fostering the Scientific and Technical Innovation of Guangzhou University.

Conflicts of Interest: The authors declare no conflict of interest.

\section{References}

1. Zhu, S.; Guo, X.; Liu, X. Bearing capacity of aluminum alloy members under eccentric compression at elevated temperatures. Thin Walled Struct. 2018, 127, 574-587. [CrossRef]

2. Buchanan, A.H. Fire Engineering Design Guide; University of Canterbury: Christchurch, New Zealand, 2001.

3. Du, Y.; Li, G.Q. A new temperature-time curve for fire-resistance analysis of structures. Fire Saf. J. 2012, 54, 113-120. [CrossRef]

4. Xue, S.D.; Xiong, J.L.; Li, Y. Empirical formula for air temperature in large space structure under fire. J. Beijing Univ. Technol. 2013, 39, 203-207.

5. Fan, S.; Shu, G.P.; She, G.J.; Liew, J.Y.R. Computational method and numerical simulation of temperature field for large-space steel structures in fire. Adv. Steel Constr. 2014, 10, 151-178. [CrossRef]

6. McGrattan, K.; McDermott, R.; Hostikka, S.; Floyd, J. Fire Dynamics Simulator (Version 5) User's Guide; NISTIR: Baltimore, MD, USA, 2010.

7. Liu, M.; Zhao, J.; Sun, C.; Wang, F. Anti-fire experiment and finite element analysis of steel planar circular tubular truss. Low Temp. Archit. Technol. 2012, 2, 27-29.

8. Zhao, J.S.; Shen, W.P.; Nonlinear, F.E. Analysis of steel frames at elevated temperatures. J. Shanghai Jiao Tong Univ. 1996, 30, 55-59.

9. Bradford, M.A. Long-span shallow steel arches subjected to fire loading. Adv. Struct. Eng. 2010, 13, 501-511. [CrossRef]

10. Moss, P.J.; Dhakal, R.P.; Bong, M.W. Design of steel portal frame buildings for fire safety. J. Constr. Steel Res. 2009, 65, 1216-1224. [CrossRef] 
11. Pyl, L.; Schueremans, L.; Dierckx, W. Fire safety analysis of a 3D frame structure based on a full-scale fire test. Thin Walled Struct. 2012, 61, 204-212. [CrossRef]

12. Lu, L.; Yuan, G.; Huang, Z. Performance-based analysis of large steel truss roof structure in fire. Fire Saf. J. 2017, 93, 21-38. [CrossRef]

13. Richard, L.J.Y.; Tang, L.; Choo, Y.S. Advanced analysis for performance-based design of steel structures exposed to fires. J. Struct. Eng. 2002, 128, 1584-1593. [CrossRef]

14. Milke, J.A. Performance-based analysis methods to determine the fire resistance of structural members. In Proceedings of the Structures Congress, Washington, DC, USA, 18 May 2001; pp. 1-11. [CrossRef]

15. Parkinson, D.L.; Kodur, V. Performance based design of structural steel for fire conditions a calculation methodology. In Proceedings of the Structures Congress, St. Louis, MO, USA, 10 October 2006; pp. 1-10. [CrossRef]

16. Farzampour, A. Evaluating shear links for use in seismic structural fuses. Ph.D. Thesis, Virginia Tech, Blacksburg, VA, USA, 2019.

17. Farzampour, A.; Eatherton, M.R. Investigating limit states for butterfly-shaped and straight shear links. In Proceedings of the 16th European Conference on Earthquake Engineering, 16ECEE, Thessaloniki, Greece, 18-21 June 2018; pp. 18-21.

18. Farzampour, A.; Eatherton, M.R. Parametric study on butterfly-shaped shear links with various geometries. In Proceedings of the 11th National Conference on Earthquake Engineering, 11NCEE, Los Angeles, CA, USA, 25-29 June 2018; pp. 25-29.

19. Farzampour, A.; Eatherton, M.R. Yielding and lateral torsional buckling limit states for butterfly-shaped shear links. Eng. Struct. 2019, 180, 442-451. [CrossRef]

20. Standard for Smoke and Heat Venting (ANSI/NFPA 204-2012); American Nuclear Society Specificatioin: Austin, TX, USA, 2012.

21. Technical Specification for Fire Protection of Steel Structure Buildings (CECS 200-2006); China Planning Press: Beijing, China, 2006.

22. EN 1993-1-2. Eurocode 3: Design of steel structures-Part 1.2: General rules-Structural fire design [Authority: The European Union Per Regulation 305/2011, Directive 98/34/EC, Directive 2004/18/EC]. 2005. 